University of Nebraska - Lincoln

DigitalCommons@University of Nebraska - Lincoln

January 2000

\title{
EFFECTS OF TEMPERATURE ANOMALIES ON THE PALMER DROUGHT SEVERITY INDEX IN THE CENTRAL UNITED STATES
}

Q. Steven $\mathrm{Hu}$

University of Nebraska - Lincoln, qhu2@unl.edu

Gary D. Willson

Northern Prairie Wildlife Research Center, USGS, and Department of Soil and Atmospheric Sciences,

University of Missouri-Columbia, Columbia, MO, USA

Follow this and additional works at: https://digitalcommons.unl.edu/natrespapers

Part of the Natural Resources and Conservation Commons

Hu, Q. Steven and Willson, Gary D., "EFFECTS OF TEMPERATURE ANOMALIES ON THE PALMER DROUGHT SEVERITY INDEX IN THE CENTRAL UNITED STATES" (2000). Papers in Natural Resources. 99. https://digitalcommons.unl.edu/natrespapers/99

This Article is brought to you for free and open access by the Natural Resources, School of at DigitalCommons@University of Nebraska - Lincoln. It has been accepted for inclusion in Papers in Natural Resources by an authorized administrator of DigitalCommons@University of Nebraska - Lincoln. 


\title{
EFFECTS OF TEMPERATURE ANOMALIES ON THE PALMER DROUGHT SEVERITY INDEX IN THE CENTRAL UNITED STATES
}

\author{
QI HU ${ }^{\mathrm{a}, *}$ and GARY D. WILLSON ${ }^{\mathrm{b}}$ \\ ${ }^{a}$ School of Natural Resource Sciences, University of Nebraska-Lincoln, Lincoln, NE, USA \\ ${ }^{\mathrm{b}}$ Northern Prairie Wildlife Research Center, USGS, and Department of Soil and Atmospheric Sciences, \\ University of Missouri-Columbia, Columbia, MO, USA \\ Received 7 February 2000 \\ Revised 16 June 2000 \\ Accepted 29 June 2000
}

\begin{abstract}
The purpose of this study is to improve our understanding of temperature and precipitation effects on the Palmer Drought Severity Index (PDSI). Both theoretical and observational analyses were applied to separate and compare temperature and precipitation effects on PDSI. The results showed that because of the dependence of PDSI on the 'climatologically appropriate rainfall', which is a function of time and varies with surface air temperature, the PDSI can be equally affected by temperature and precipitation, when both have similar magnitudes of anomalies. Calculations using observational data further illustrated the temperature influence on PDSI in different climate regions in the central United States. The temperature effect on PDSI complicates the usage of the index in interpreting precipitation anomalies and its application in inferring precipitation variations, particularly from reconstructed PDSI. Copyright (C) 2000 Royal Meteorological Society.
\end{abstract}

KEY WORDS: central United States; interpreting reconstructed PDSI; observation; Palmer Drought Severity Index; precipitation; temperature; theoretical analysis

\section{INTRODUCTION}

The Palmer Drought Severity Index (PDSI) (Palmer, 1965) is widely used as an indicator of regional drought conditions (Karl and Koscielny, 1982; Diaz, 1983; Szinell et al., 1998; among others). It is calculated and disseminated to clients and the public on a regular basis by various agencies in different countries. In palaeoclimate studies (e.g. Stahle et al., 1985; D'Arrigo and Jacoby, 1991; Cleaveland and Stahle, 1996; Grissino-Meyer, 1996), the PDSI has been reconstructed from tree-ring chronologies and used to infer 'dry' and 'wet' periods and, in some studies, precipitation variations in past climates. Recently, the index has also been used in climate change assessment (e.g. Central Great Plains Assessment, 1999). It was calculated using model prediction data and examined for differences in frequency, intensity and duration of droughts between the current and predicted future climates.

The PDSI measures the accumulated effect of monthly rainfall deficit/surplus relative to the monthly 'climatologically appropriate rainfall', defined as rainfall needed to maintain adequate soil water content for normal (water stress free) growth of plants in a region. This appropriate rainfall is a function of time and its monthly values are calculated from surface and soil water balance among evaporation, plant transpiration, runoff and available soil water for evaporation and transpiration (Palmer, 1965; Alley, 1984). In the soil water balance, evaporation and plant transpiration are major processes affecting water loss (Monteith, 1973, 1976; Abramopoulos et al., 1988). Because evaporation and transpiration rates are determined by the deficit of vapour pressure between soil/plant surface and surface air, and vapour pressure is a function of temperature, the appropriate rainfall is a function of air temperature. Thus, the

* Correspondence to: School of Natural Resource Sciences, 237 L.W. Chase Hall, University of Nebraska-Lincoln (UNL), Lincoln, NE 68583-0728, USA; e-mail: qhu2@unl.edu. 
equal dependence of the PDSI on monthly appropriate rainfall and actual monthly rainfall underscores a significant effect of air temperature on the PDSI. This temperature effect on the PDSI, however, has not been thoroughly investigated.

Numerical experiments have been used to evaluate the influences of temperature and precipitation anomalies on the PDSI and its related indices, e.g. Palmer Hydrological Drought Index (PHDI) (Guttman, 1991). Results of these experiments showed that precipitation anomalies tend to dominate the change of PDSI in the cold season when evaporation is minimal. Temperature effect on PDSI becomes important in the warm season. However, because the response of the PDSI often lags the anomalies of temperature and precipitation by a few months (e.g. Karl, 1986) and this lag relationship is not well understood, the questions of how temperature and precipitation affect the PDSI variation and how we may interpret the PDSI in terms of precipitation and temperature anomalies remain.

The increasing usage of the PDSI, particularly in climate research and monitoring, demands answers to the above questions and invites further understanding of the index. Separating and understanding effects of temperature and precipitation on the PDSI are essential for correct use of the index to monitor droughts and in accurately interpreting temperature and precipitation anomalies contributing to the PDSI.

In this study, we separate, using a theoretical analysis, temperature and precipitation effects on the PDSI. We use observational and experimental analyses to illustrate temperature and precipitation effects on the index. In Section 2, we will develop an analytic relationship between the PDSI and anomalies of precipitation and temperature. In Section 3, we will show variations of monthly PDSI corresponding to separate anomalies of monthly temperature and precipitation. Finally, in Section 4, we discuss the significance of these results.

\section{A THEORETICAL ANALYSIS}

The PDSI is defined as

$$
\operatorname{PDSI}_{i}=0.897 P D S I_{i-1}+\frac{1}{3} Z_{i} \text {. }
$$

Here, subscripts $i$ and $i-1$ indicate current and previous months at some arbitrary time, respectively, and $P D S I_{0}=0$. The $Z_{i}$ in Equation (1), called the monthly $Z$-index, is defined as

$$
Z_{i}=(K d)_{i}
$$

where $K$ is a coefficient and

$$
d=P-\left(\alpha_{i} P E+\beta_{i} P R+\gamma_{i} P R O-\delta_{i} P L\right) .
$$

In the above, $P$ is actual monthly precipitation. The terms in the parentheses on the right-hand-side (r.h.s.) of Equation (3) combine to yield monthly 'climatologically appropriate rainfall'. In particular, $P E$ is potential evapotranspiration, $P R$ potential water recharge to soil, and $P R O$ potential runoff. Palmer (1965) used a two-layer soil model consisting of a surface layer, 'plow layer', and an underlying layer, 'root zone', and defined $P L$ as the sum of soil water of the two layers available for evapotranspiration. He called this term 'potential loss of soil water to evapotranspiration'. The four coefficients in Equation (3) are defined as

$$
\alpha_{i}=\overline{E T}_{i} / \overline{P E}_{i}, \beta_{i}=\bar{R}_{i} / \overline{P R}_{i}, \gamma_{i}=\overline{R O}_{i} / \overline{P R O}_{i}, \delta_{i}=\bar{L}_{i} / \overline{P L}_{i},
$$

where the overbar denotes a long-term average of the parameter values for the $i$ th month. The numerators in the above four expressions are long-term monthly averages of evapotranspiration, soil water recharge, runoff and available soil water amount, respectively.

Using the recursive relation of $P D S I_{i}$ and $P D S I_{i-1}$ we can rewrite Equation (1) as 


$$
\operatorname{PDSI}_{i}=\sum_{m=0}^{i} \frac{c^{m}}{3} Z_{i-m}
$$

This new formula of PDSI indicates how soil dryness/wetness anomalies of previous months affect the PDSI value of the $i$ th month. Because $c=0.897<1$ and $m$ is a positive integer, the effect of previous months on the index gradually decreases as $(i-m)$ increases. Soil wetness anomaly in the $i$ th month has a full impact on the index value for that month. The simple form of Equation (5) for $Z$ and the PDSI also indicates that the task of examining separate effects of precipitation and temperature anomalies on the PDSI can be carried out by examining the relationship between $Z$ and anomalies of precipitation and temperature.

Rearranging the terms in Equation (3), we have

$$
d=(P-S)-\alpha P E .
$$

Here, we have combined the last three terms in the parentheses on the r.h.s of Equation (3) into term $S$. Therefore, $(P-S)$ yields actual available soil water for evaporation and transpiration from rainfall events in a specified time interval, e.g. one month. The term $\alpha P E$ is total monthly loss of soil water by evapotranspiration. When this term is larger than the first term, the monthly rainfall is inadequate to maintain the 'climatologically required' soil water and the soil suffers a net loss of water by an amount of $\alpha P E-(P-S)$. In this situation, the available soil water decreases to meet evapotranspiration demand and a drought condition develops. Because $S$ is determined by topography and physical and hydraulic properties of soils at a site and is independent of surface air temperature, it can be represented further as a fraction of total precipitation of the month, that is, $S=\kappa P$. In this expression, $0 \leq \kappa \leq 1$, and $0 \leq \kappa$ came from the fact that $\kappa$ defines the fraction of monthly precipitation used in runoff, recharge to soil and contribution to the storage of the available soil water, and these contributions are zero when monthly rainfall is zero. Mathematically, this is justified by the fact that the undefined expression $S / P$ approaches zero when both $P$ and $S$ are zero.

Only $P E$ in Equation (6) is dependent on air temperature. The coefficient of this term, $\alpha$, satisfies $0<\alpha<1$, and is nondimensional. Applying Thornthwaite's (1948) calculation method for $P E$, which has been used in calculation of the PDSI (Palmer, 1965; Karl, 1986), we have $P E=\eta T^{a}$, where $T$ is monthly mean surface air temperature in degrees Celsius, $\eta=1.6(10 / I)^{a(I)} T^{a(I)}$ with $I$ being the heat index (Thornthwaite, 1948) and $a$ a function of $I$ given in Thornthwaite (1948). Note that $\eta$ has a dimension $[\mathrm{L}][\mathrm{K}]^{-1}$, where $\mathrm{L}$ is length and $\mathrm{K}$ is Kelvin, and $\eta T$ has a length unit similar to the precipitation unit. Combining these terms, we can rewrite Equation (6) as

$$
d=(1-\kappa) P-\alpha \eta T^{a} .
$$

Differentiating Equation (7) with $T$ and $P$ and writing the result in a finite difference form yields

$$
\Delta d=(1-\kappa) \Delta P-\left(\alpha \eta a T^{a-1}\right) \Delta T .
$$

This equation shows effects of temperature and precipitation anomalies on changes of $d$ and, hence, the $Z$-index. In Equation (8), change of $d$ is linearly dependent on precipitation anomaly with the coefficient $(1-\kappa)$. The dependence of $d$ on temperature anomalies is a nonlinear function of temperature itself. According to Thornthwaite (1948), $\eta=0.18$ in the central United States. In a temperature range of $0-40^{\circ} \mathrm{C}, T^{[a(I)-1]}$ ranges from 0 to 5 . In a more realistic temperature range of $20-40^{\circ} \mathrm{C}$ for summer, $T^{[a(I)-1]}$ varies between 3.5 and 5 . With these values, the coefficient of the temperature perturbation term in Equation (8) varies between 0.5 and 0.8. Finally, because $(1-\kappa)$ varies in a similar value range, the variation of $d$ and, hence, monthly $Z$ is about equally dependent on air temperature anomaly and rainfall anomaly. In other words, monthly contributions of temperature and precipitation anomalies to total PDSI are nearly equal when they have similar magnitudes of anomalies.

Equation (8) separates the effect of temperature and precipitation on the PDSI. It shows that positive anomalies of monthly rainfall will yield a positive $d$ perturbation. If there coexists a negative anomaly in monthly temperature, a temperature effect will enlarge this positive anomaly of $d$. Together these will yield a positive value of $Z$ and contribute to a positive PDSI. On the other hand, a large positive anomaly 
of temperature could override the effect of a smaller positive rainfall anomaly on variation of $d$ to result in a net negative value of $Z$ and cause a negative PDSI. Similarly, for a negative monthly rainfall anomaly, the $Z$-index of the month can still be positive if temperature is significantly cooler than the 'appropriate' temperature corresponding to 'appropriate rainfall' of the month.

The above analysis shows the effect of monthly temperature and precipitation anomalies on monthly $Z$-index values. The linear relationship of Equation (5) indicates that this effect will be linearly added over a dry period to determine the PDSI for the period.

The relationship between the PDSI and temperature and precipitation anomalies is reasonable for a drought monitoring index, because droughts develop from combined effect of both precipitation and temperature anomalies on soil water availability to plants. However, because the PDSI variations can be significantly affected by temperature anomalies and are not necessarily consistent with precipitation fluctuations, using the PDSI to interpret precipitation variations in past climates could lead to ambiguous conclusions, especially when variations of either precipitation or temperature are unknown.

\section{AN OBSERVATIONAL ANALYSIS}

In this section, we use climate data and calculated $Z$-index and PDSI to further illustrate the above theoretical results and separate the effects of precipitation and temperature on the PDSI.

\subsection{Data and method}

The climate data used in this analysis cover the southeast portion of Missouri (Region 1) and the central Great Plains of the United States (Region 2) (Figure 1). The former has a humid temperate climate and the latter has a dry temperate climate. Historical monthly precipitation and temperature data for the two regions were obtained from the US National Climatic Data Center (NCDC). The data were quality checked and are continuous.

A calculation method of $Z$-index and PDSI developed at the NCDC was used. Soil parameters for each of the regions were obtained from US Department of Agriculture (USDA) Soil Testing Laboratory at Lincoln, NE.

\subsection{Results}

Using the historical data, we calculated $Z$-index and identified all the months which had $Z$ values close to neutral $(Z=0)$. We further examined monthly temperature and precipitation for those months and selected the months that had near normal monthly temperature and precipitation. This neutral climate condition serves as the basis for comparison and identification of responses of $Z$ to temperature and precipitation anomalies. We then recalculated $Z$-index, after adding a perturbation to the monthly

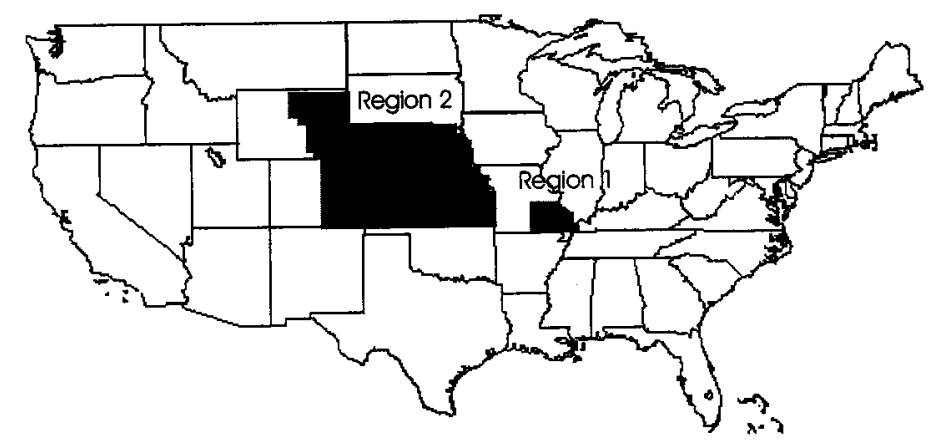

Figure 1. The geographical location of the study areas. Region 1 covers the eastern Ozark Plateau in Missouri and Region 2 covers the Central Great Plains of the US (modified from the Central Great Plains Assessment, 1999) 
temperature and precipitation, respectively, and examined the response of $Z$ to the perturbation. According to Equation (5), the response of $Z$ is the response of PDSI to temperature and precipitation anomalies.

Guttman (1991) reported a similar analysis but with a different approach in which he specified a month, e.g. November (see figures 1 and 2 in Guttman, 1991), and defined a neutral condition based on PHDI. He calculated PHDI from perturbed temperature and precipitation in a perpetual November time series, and determined PHDI sensitivity. In this study, we used composite monthly conditions from real data and examined $Z$ and PDSI responses to temperature and precipitation anomalies. Another aspect of the study by Guttman (1991), relevant to the results described below, is that Guttman used 'temperature perturbations of plus and minus 1, 3, 5, and 10 degrees of Fahrenheit', and 'precipitation perturbations of 25 to 200 percent of the long-term, monthly averaged value' in his analysis. For the sites used in his study, such temperature perturbations were within $10-25 \%$ of the mean monthly temperatures. They were smaller, percentage-wise, than the smallest precipitation perturbations used in his study. In our study, we examine responses of $Z$ to temperature and precipitation anomalies of the same magnitude relative to their mean monthly values, and discuss the difference between the magnitude of anomalies of temperature and precipitation as a separate issue.

Figure 2 shows average change in $Z$ over the month of June from our procedure for Region 2 . The results indicate that monthly $Z$-index changed from near neutral $(-0.12)$ to -1.10 in response to a temperature increase of $1-2.5^{\circ} \mathrm{C}$, equivalent to $5-10 \%$ of monthly mean temperature for June in the region. It changed from -0.12 to -0.46 , corresponding to precipitation decreases of similar magnitudes, i.e. same percentage of monthly mean precipitation. When we decreased temperature or increased precipitation by the proportional amounts, $Z$-index changed from near neutral to positive values of 0.80 and 0.24 , respectively. Similar responses of $Z$ to temperature and precipitation changes also were observed for Region 1. These changes contributed to monthly PDSI variations in those regions.

These results confirm that for changes of similar magnitude of temperature and precipitation the $Z$-index and PDSI were about equally affected, with a slightly bigger effect from temperature anomalies. They are consistent with the theoretical results of the previous section and suggest that the PDSI cannot directly measure the fluctuations of precipitation when temperature anomalies coexist. They are also

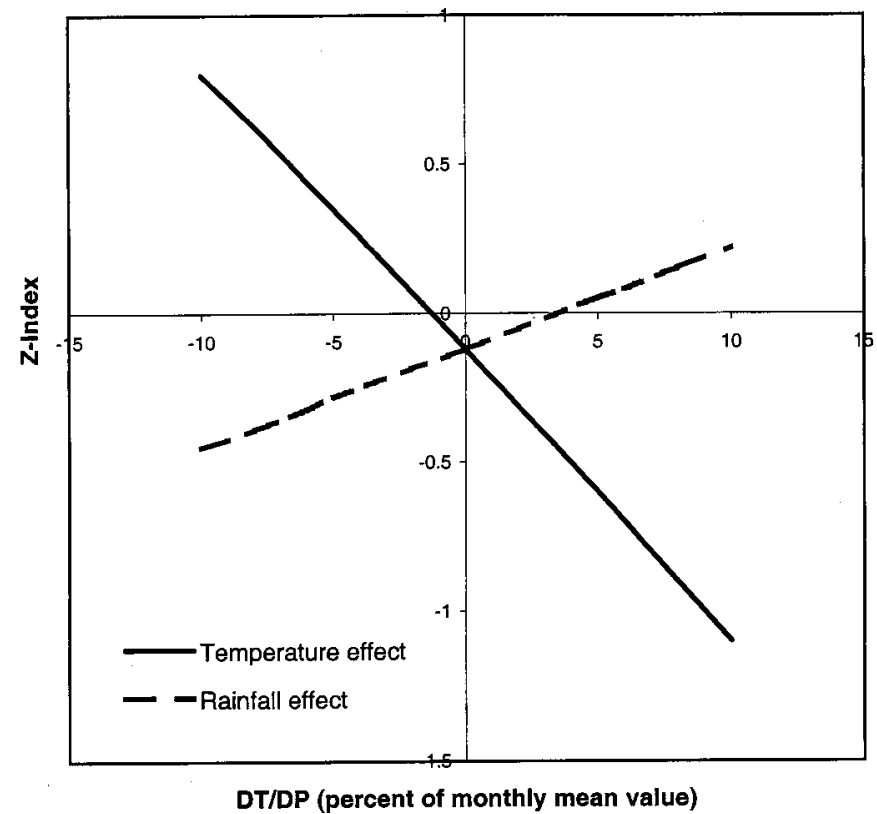

Figure 2. Response of $Z$-index to temperature and precipitation perturbations for June in Region 2 

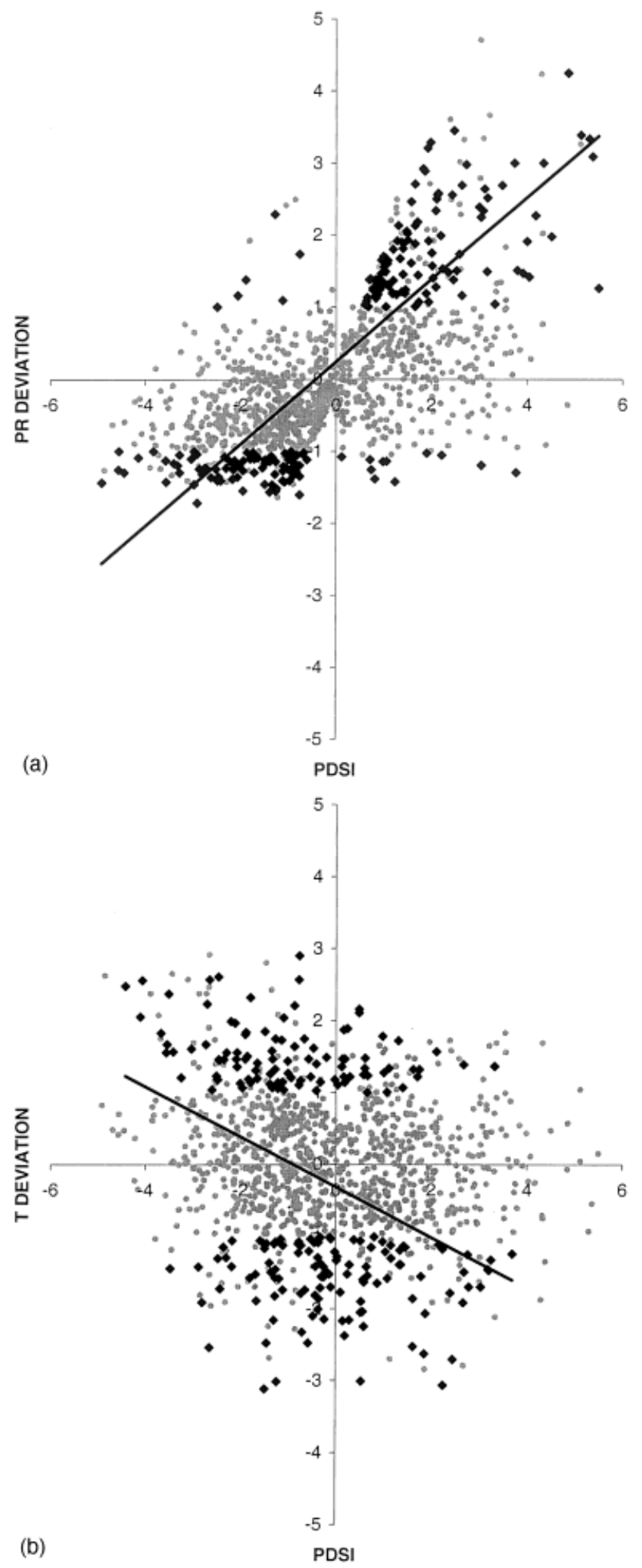

Figure 3. Correlations of PDSI versus regional average precipitation (a), temperature (b) and correlation of regional average precipitation versus temperature (c) for Region 1 (see text for details) 


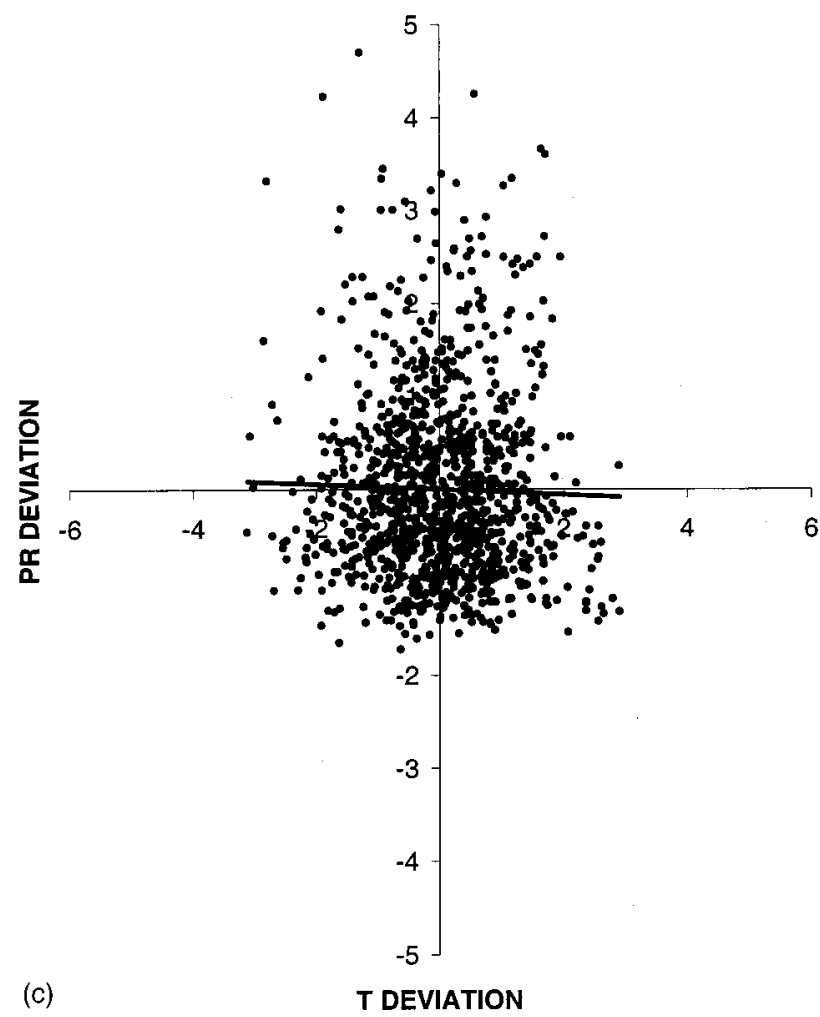

Figure 3 (Continued)

consistent with results of calculations by other methods. For example, Abramopoulos et al. (1988) show in their general circulation modelling study that evaporation and transpiration can consume up to $80 \%$ of rainfall. In addition, they found that the efficiency of drying due to temperature anomalies is as high as that due to rainfall shortages.

Because the temperature fluctuation is smaller than the precipitation fluctuation, we observe larger responses of $Z$ and PDSI to precipitation anomalies. Our examination of monthly temperature and precipitation data in Region 1 (1897-1995) and Region 2 (1948-1995) showed that 1 standard deviation (S.D.) of monthly temperature variation is about $10 \%$ of monthly average temperature for warm season months. On the other hand, 1 S.D. of monthly precipitation variation is about $50 \%$ of monthly mean precipitation in those months. Depending on a region's climate, large precipitation fluctuations can have considerable impact on PDSI. However, temperature anomalies are often dominant in PDSI variations from time to time. The PDSI variations actually result from a combination of both temperature and precipitation anomalies.

To further illustrate the latter point, we present in Figures 3 and 4 the correlation of PDSI and anomalies of precipitation and temperature for Regions 1 and 2, respectively. The PDSI was calculated from monthly precipitation and temperature for the period 1897-1995 for Region 1 and 1948-1995 for Region 2. Because there were often both precipitation and temperature anomalies in a month and both could be large for some months, we selected the months that had either temperature anomalies larger than the precipitation anomalies or precipitation anomalies larger than temperature anomalies, and divided them into two groups. Specifically, Group 1 has all the months that have absolute precipitation anomalies greater than or equal to 1 S.D. of the monthly means but have absolute temperature anomalies smaller than 1 S.D. of the monthly means for the same months. Group 2 has the same criterion but with precipitation anomalies smaller than the temperature anomalies. Group 1 has 216 elements (months) and Group 2 has 219 elements among 1176 monthly data for Region 1. There are 90 and 92 elements in 

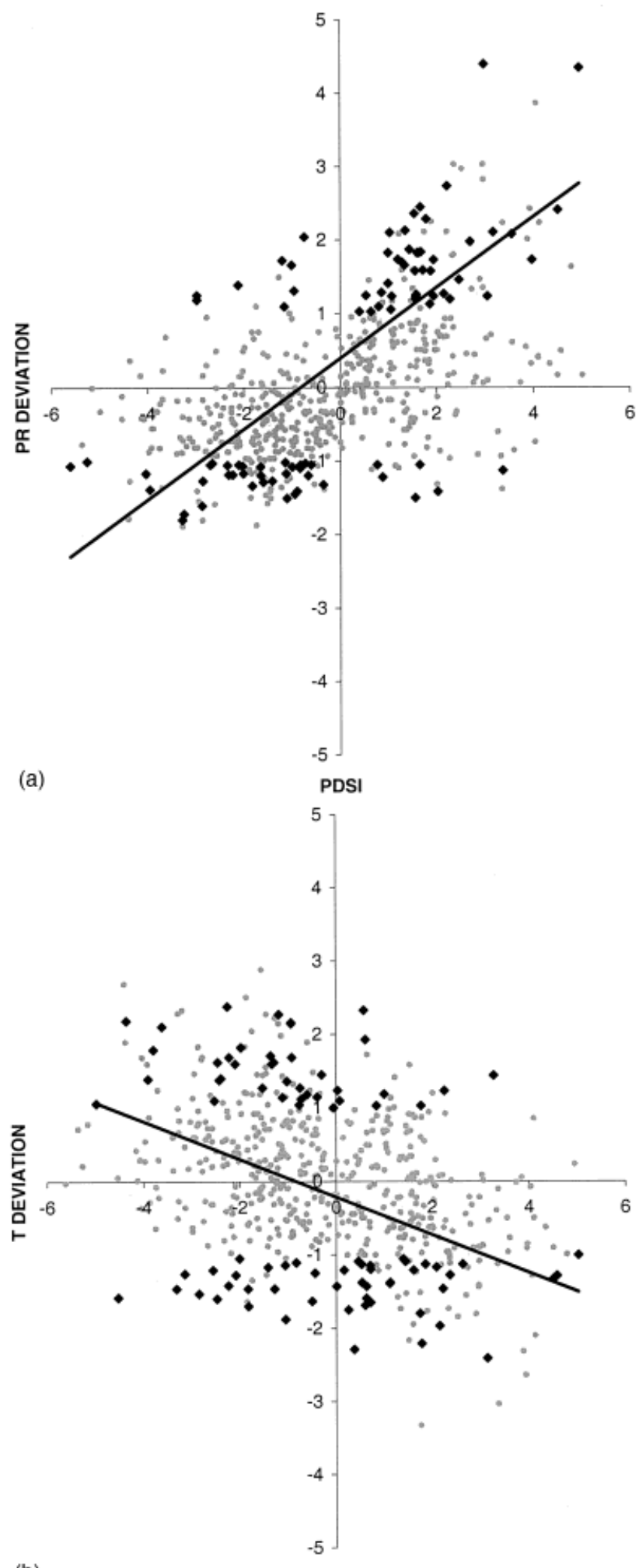

(b)

PDSI

Figure 4. Correlations of PDSI versus regional average precipitation (a), temperature (b) and correlation of regional average precipitation versus temperature (c) for Region 2 (see text for details) 


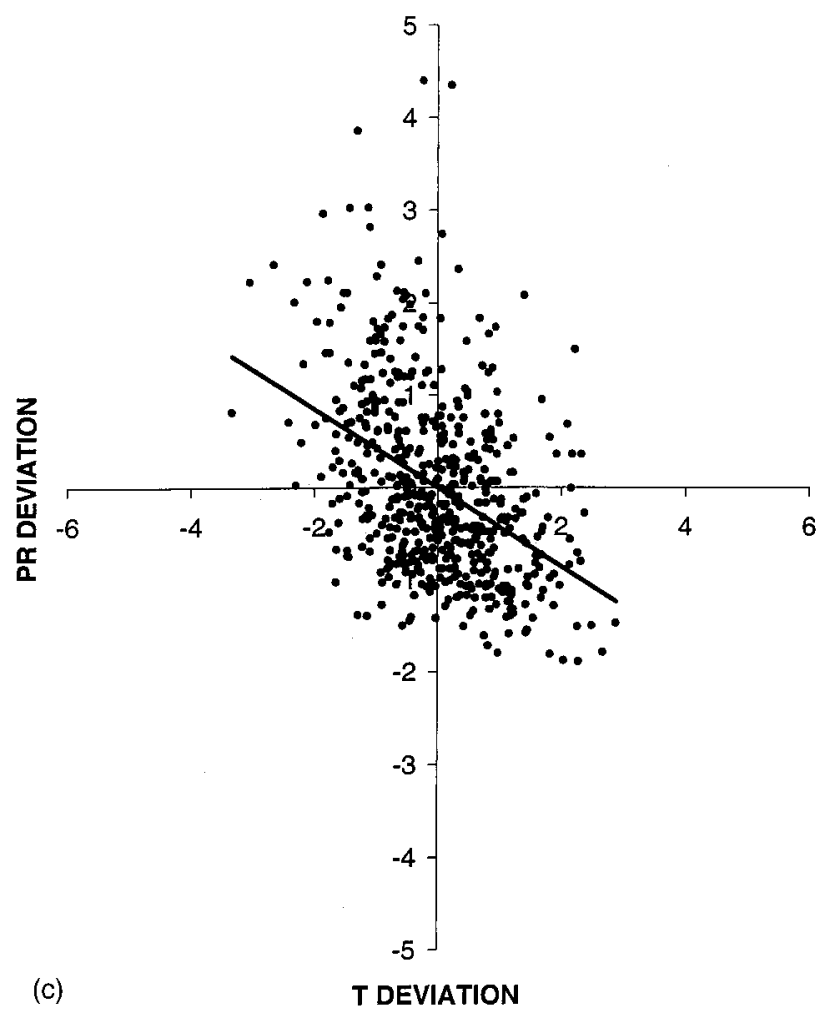

Figure 4 (Continued)

Group 1 and Group 2, respectively, among 564 monthly data for Region 2. In these two groups, either the precipitation anomaly or the temperature anomaly was the major effect on PDSI. Thus, we can separately examine the effect of temperature and precipitation on PDSI.

Figure 3(a) shows the relation of PDSI and monthly precipitation anomaly for Region 1 . The black dots show the data from Group 1 with large monthly precipitation anomalies, and grey dots show all the 1176 data in the 98 -year period. There is a positive correlation of 0.79 between the PDSI and monthly precipitation anomaly. Figure 3(b) shows a similar plot but for monthly temperature and PDSI, which reveals a negative correlation. The correlation coefficient is -0.35 . Although this is smaller than the correlation coefficient between the PDSI and precipitation anomaly, it is above the $95 \%$ confidence level, 0.32, for the dataset (Steel and Torrie, 1960). It indicates that the temperature effect on the PDSI is statistically significant when the precipitation anomaly is not large. It is also worth pointing out that the number of elements in the two groups are nearly equal, suggesting an equal chance for either the precipitation or temperature anomaly to affect the PDSI for the region.

Figure 3(c) shows that there is no relationship between precipitation and temperature anomalies in Region 1. This result further indicates that the dependence of PDSI on temperature shown in Figure 3(b) is uniquely explained by temperature anomalies.

Figure 4 shows similar calculations for Region 2. Again, the correlation between the PDSI and temperature anomalies is statistically significant although its coefficient $(-0.40)$ is smaller than the correlation coefficient between the PDSI and precipitation anomalies (0.69) for this region. However, because there is a negative correlation between the temperature and precipitation anomalies in this region, as shown in Figure 4(c), the negative correlation between the temperature anomaly and PDSI shown in Figure 4(b) might not be explicitly attributable to the temperature anomalies (Figure 4(a)).

To resolve this ambiguity in the Region 2 results, we examined the monthly data of individual stations in Nebraska, which is in Region 2. We identified cases at different stations that had near normal rainfall but anomalous temperatures. A typical case is shown in Figure 5 for 1977-1979 at Auburn, NE. 


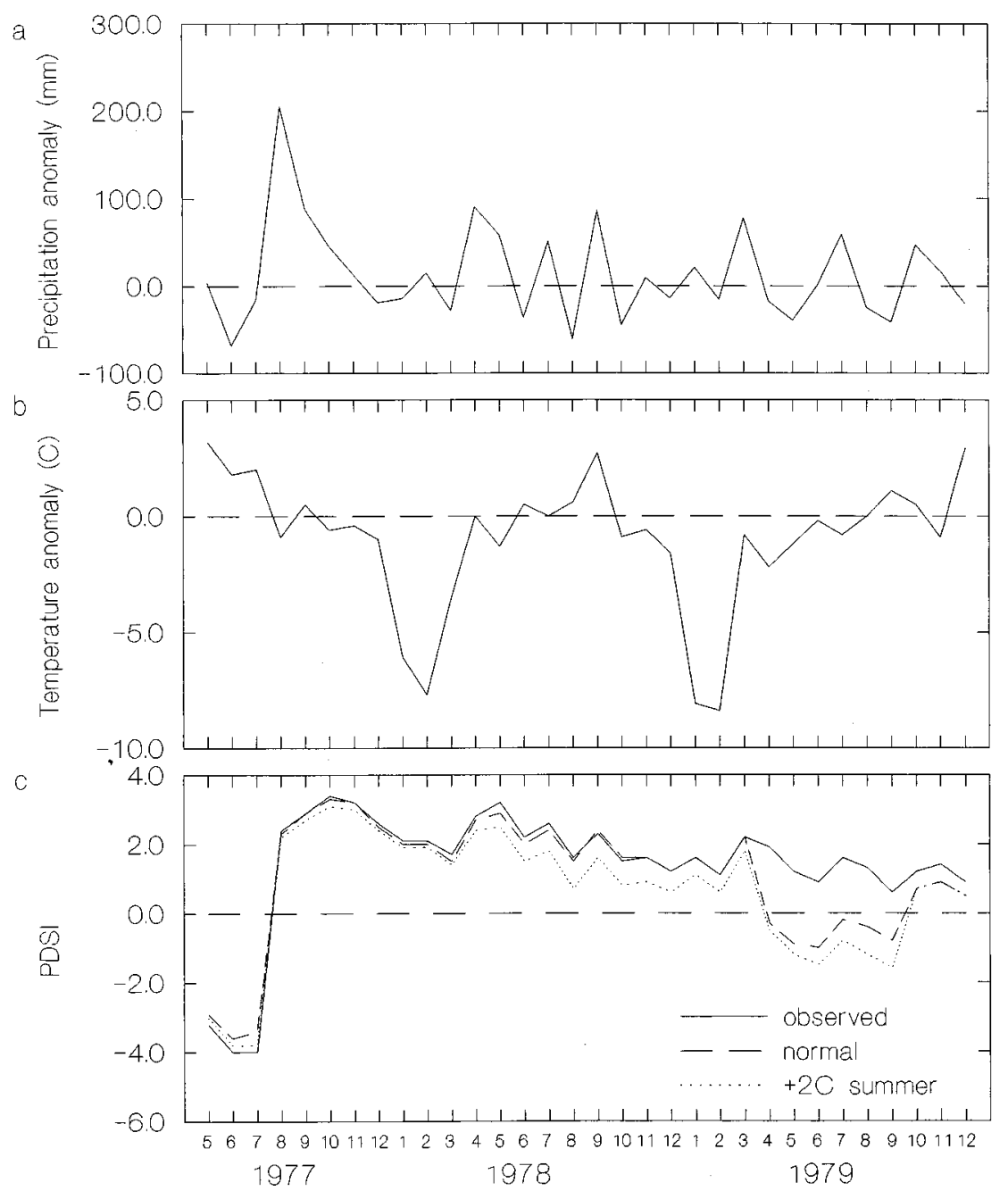

Figure 5. Variations of monthly precipitation anomaly (a), temperature anomaly (b) and corresponding PDSI (c) for 1977-1979 at Auburn, NE. The dashed-line in (c) shows calculated PDSI using monthly mean temperatures for the time period, and the dotted-line the PDSI using monthly mean temperatures plus a $2{ }^{\circ} \mathrm{C}$ increase of June, July and August temperatures

The solid curves in Figure 5(a) and (b) show recorded temperature and precipitation anomalies for the period. It was a very wet period from August to October 1977. The August rainfall amount was $206 \mathrm{~mm}$ above the average of 1897-1995 and was close to 3 S.D. of the station normal precipitation for that month. The soil remained wet through February of 1978. From June 1978 to December 1979, precipitation fluctuated around normal and the overall average was slightly above normal. There were two major cold periods in the winters of 1977-1978 and 1978-1979. The negative anomalies in temperature in the latter case lasted through most of the summer of 1979. The corresponding PDSI for the period is shown by the solid curve in Figure 5(c).

We recalculated the PDSI after removing the temperature anomalies by adjusting temperatures to their monthly average values. This adjustment was to single out the contribution of cold temperatures to positive PDSI for the period. The recalculated PDSI is shown by the dashed curve in Figure 5(c). The differences between the solid and dashed curves in Figure 5(c) show that the large precipitation anomalies in summer and autumn 1977 had a dominant effect on PDSI. There was little temperature impact on PDSI under such wet conditions. However, when precipitation was close to normal after the wet period in 1977, temperature effect on the PDSI became significant. In particular, when the negative temperature 
anomalies were removed in spring and summer of 1979, PDSI changed from an average positive value of 1.5 to an average -1.0 for the months of April-September 1979. This showed that the positive PDSI in the summer months (June-August) had resulted primarily from the cold temperature anomalies in that period. An additional test showed that a temperature anomaly of $+2{ }^{\circ} \mathrm{C}$ in the summer months would result in an average value - 1.5 PDSI for the period (dotted line in Figure 5(c)). These results illustrate temperature impacts on PDSI. Because such an effect can be significant, it is difficult to decide whether a period of negative PDSI indicates a period of precipitation deficit or warm temperature anomalies.

The temperature effect on the $Z$-index and, thus, PDSI is shown by consistent changes of monthly $Z$-index values and temperature in Region 1. Figure 6 shows variations of normalized July precipitation and temperature for the region and $Z$-index of the same month over the period 1900-1990. There was a significant decrease of the variance of $Z$-index after 1955 (Figure 6(c)). In the same period, there was a decrease of the variance of July temperature (Figure 6(b)), but an increase of the variance of July precipitation (Figure 6(a)). The $Z$-index variation shows a behaviour similar to that of monthly temperature variation of the region but not monthly precipitation variation.

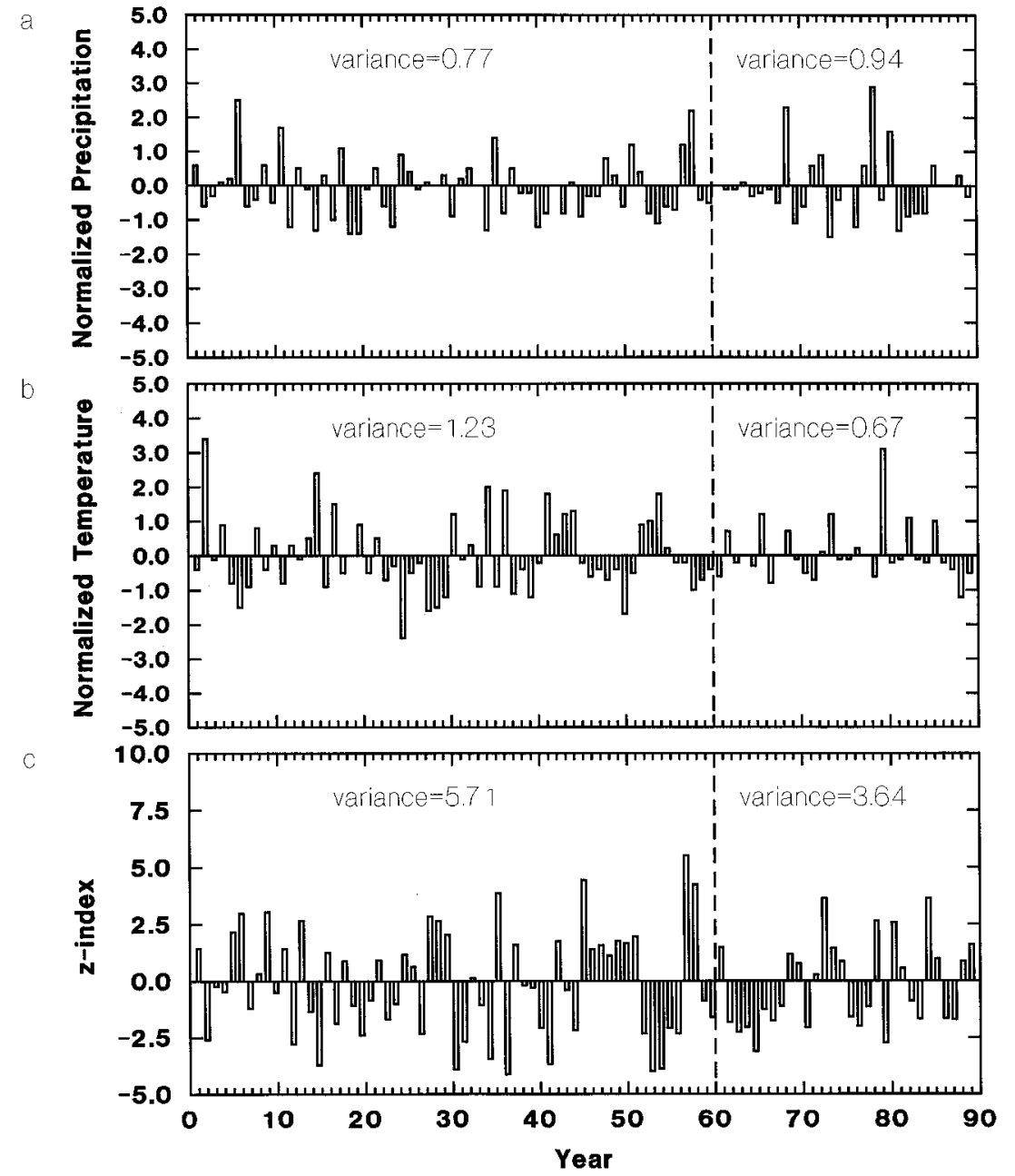

Figure 6. Variations of July normalized precipitation (a), temperature (b) and PDSI (c) for Region 1 


\section{CONCLUDING REMARKS}

The PDSI measures accumulated difference of actual monthly rainfall and monthly 'climatologically appropriate rainfall', which is a function of time and is affected by temperature variations. Our theoretical analysis separated temperature and precipitation effects on the PDSI. The scale analysis further showed that when soil properties and topography are fixed, the PDSI is about equally affected by precipitation and temperature anomalies when both have anomalies of similar magnitude.

The presence of a negative correlation of the variations of precipitation and temperature in many climate regions (Karl and Quayle, 1981; Madden and Williams, 1981) may have masked the temperature effect on PDSI by precipitation effect. Additionally, fluctuations of precipitation with large amplitudes in some regions strengthens the precipitation effect on PDSI. The PDSI in these situations represents the effect of precipitation anomalies on soil water conditions. However, as we showed, even in these climate regions temperature effects contribute to the PDSI. Our calculations showed that temperature effect dominated the sign of PDSI when precipitation anomalies were relatively small. For regions that show an absence of a negative correlation of variations of temperature and precipitation, a statistically significant negative correlation between PDSI and temperature variations indicated the impact of temperature on the PDSI.

These results have been obtained using data from two regions in the central United States that have contrasting humid and dry temperate climate conditions. Although regional limitations may prevent a direct generalization of some of the results to other climate regions in the world, this study sheds light on the importance of temperature effect on the PDSI.

The temperature effect on the PDSI complicates the interpretation of precipitation anomalies using the PDSI and, thus, application of the index to inferring precipitation variations, particularly from reconstructed PDSI. One major uncertainty is whether the reconstructed PDSI from tree-rings can be interpreted as an indicator of past precipitation variations. Because of this uncertainty, the historical wet and dry periods attributed to reconstructed PDSI variations may not be caused by precipitation anomalies alone. Therefore, we suggest caution in applying the PDSI in climate studies as well as climate monitoring.

\section{ACKNOWLEDGEMENTS}

We thank Dr Michael Hayes of the International Drought Mitigation Center for providing the PDSI calculation code and for useful discussions. We also thank Cynthia Hays for performing some of the calculations, and Dr Kenneth Hubbard of US High Plains Climate Center and two anonymous reviewers for their suggestions that led to improvement of this manuscript. Q. Hu thanks Ozark Highland Global Change Research Program of the US Geological Survey (Cooperative Agreement 1445-CA09-95-0069) and USDA (Cooperative Agreement 68-7428-9-459Y) for support of this work.

\section{REFERENCES}

Abramopoulos F, Rosenzweig C, Choudhury B. 1988. Improved ground hydrology calculations for global climate models (GCMs): Soil water movement and evapotranspiration. Journal of Climate 1: 921-941.

Alley WM. 1984. The Palmer Drought Severity Index: limitations and applications. Journal of Climate and Applied Meteorology 23: $1100-1109$.

Central Great Plains Assessment. 1999. Climate change impacts in the Central Great Plains. Loveland, CO, March 22-24, 1999. Colorado State University; 200 pp.

Cleaveland MK, Stahle DW. 1996. Variability of hydrological drought in the Ozark Highlands, 1680-1980. In Tree Rings, Environment and Humanity, Dean JS, Meko DM, Swetnam TW (eds). Department of Geosciences, University of Arizona; 43-50.

D'Arrigo RD, Jacoby GC. 1991. A 1000-year record of winter precipitation from northwestern New Mexico, USA: A reconstruction from tree-rings and its relationship to El Nino and the Southern Oscillation. Holocene 1: 95-101.

Diaz HF. 1983. Some aspects of major dry and wet periods in the contiguous United States, 1895-1981. Journal of Climate and Applied Meteorology 22: 3-16.

Grissino-Meyer HD. 1996. A 2129-year reconstruction of precipitation for northwestern New Mexico, USA. In Tree Rings, Environment and Humanity, Dean JS, Meko DM, Swetnam TW (eds). Department of Geosciences, University of Arizona; $191-204$ 
Guttman NB. 1991. A sensitivity analysis of the Palmer Hydrologic Drought Index. Water Resources Bulletin 27: $797-807$.

Karl TR. 1986. The sensitivity of the Palmer Drought Severity Index and Palmer's Z-Index to their calibration coefficients including potential evapotranspiration. Journal of Climate and Applied Meteorology 25: 77-86.

Karl TR, Koscielny AJ. 1982. Drought in the United States: 1895-1981. Journal of Climatology 2: 313-329.

Karl TR, Quayle RG. 1981. The 1980 summer heat wave and drought in historical perspective. Monthly Weather Review 109: 2055-2073.

Madden RA, Williams J. 1981. The correlation between temperature and precipitation in the United States and Europe. Monthly Weather Review 106: 142-147.

Monteith JL. 1973. Principles of Environmental Physics. Elsevier: New York.

Monteith JL. 1976. Evaporation and surface temperature. Quarterly Journal of Royal Meteorological Society 107: 1-27.

Palmer WC. 1965. Meteorological drought. US Weather Bureau, Research Paper No. 45, 58 pp.

Stahle DW, Cleaveland MK, Hehr JG. 1985. A 450-year drought reconstruction for Arkansas, United States. Nature 316: 530-532.

Steel RGD, Torrie JH. 1960. Principles and Procedures of Statistics. McGraw-Hill: New York; 183-191, Chapter 10.

Szinell CS, Bussay A, Azentimrey T. 1998. Drought tendencies in Hungary. International Journal of Climatology 18: 1479-1491.

Thornthwaite CW. 1948. An approach toward a rational classification of climate. Geographical Review 38: 55-94. 